\title{
Dis/pares Marosa di Giorgio-Idea Vilariño y el canon poético femenino en Uruguay
}

\author{
Ana Inés Larre Borges \\ Departamento Investigaciones Literarias \\ Biblioteca Nacional de Uruguay
}

En la escena poética, dos son multitud. La tradición del poeta laureado, de los juegos florales, han fomentado, de modo más persistente en la poesía que en otros géneros, una razón de exclusividad y primacía. En los comienzos se admite y se espera que los poetas jóvenes anden en grupos, pero la madurez reclama una consagración. Se transita de una democracia festivamente desordenada, fraterna o belicosa, a un orden de castas que progresa hasta la soledad de la cima. El Uruguay se ha complacido en creer que esas alturas están reservadas a las poetas mujeres, una estirpe que se fundó en el Novecientos y que ya forma parte del tesoro nacional. Nadie quiere poner en duda patrimonio tan seguro, de modo que la categoría ha atravesado incólume nuestra historia sin que ser nunca puesta en cuestión o al menos indagada. Lo que en otros lados se denomina con jerga ascéptica un "subsistema del campo literario", en Uruguay es una dinastía. Periódicamente se dirime -es verdad que tácitamente- quién ocupará el lugar de Delmira. Delmira, María Eugenia, Juana, Ida, Idea, Amanda, Marosa, Circe, el linaje es regio y por eso las llamamos por su nombre de pila. No seré quien se atreva a intentar deponer una monarquía tan ostensiblemente sólida, pero me gustaría atender al modo en que las propias poetas lidiaron con el peso de esa tradición. Y hacerlo con dos grandes poetas, parcialmente coetáneas, opuestas en su persona y en su obra.

Idea Vilariño y Marosa di Giorgio se nos figuran habitantes de realidades alternas y excluyentes. Sus poéticas y su política fueron antagónicas y así también su legado. Sin embargo, compartieron la escena literaria uruguaya en tiempos de alta temperatura cultural y política y en el tiempo hostil y vacío de la dictadura. Y, al final de sus vidas, habitaron la ambigua democracia del Uruguay posdictatorial y posmoderno.

Pertenecieron a generaciones diferentes y contiguas, Idea (1920-2009) fue protagonista de la autoconsciente generación del medio siglo, o del 45, o de Marcha, que modeló la cultura uruguaya por otro medio siglo, en tanto Marosa (1932-2004), doce años menor, vivió con lánguida indiferencia su pertenencia a una generación exigua y difusa.

Ambas fueron a su modo legendarias a partir de su poesía, pero también de sus figuras de autor. Es algo que no pasa con Amanda Berenguer, Ida Vitale o Circe Maia. Idea y Marosa -antitéticas- están rodeadas de un aura mítica. Observarlas en la caricatura de un mismo dibujante-(Ombú)- puede abreviar explicaciones. 

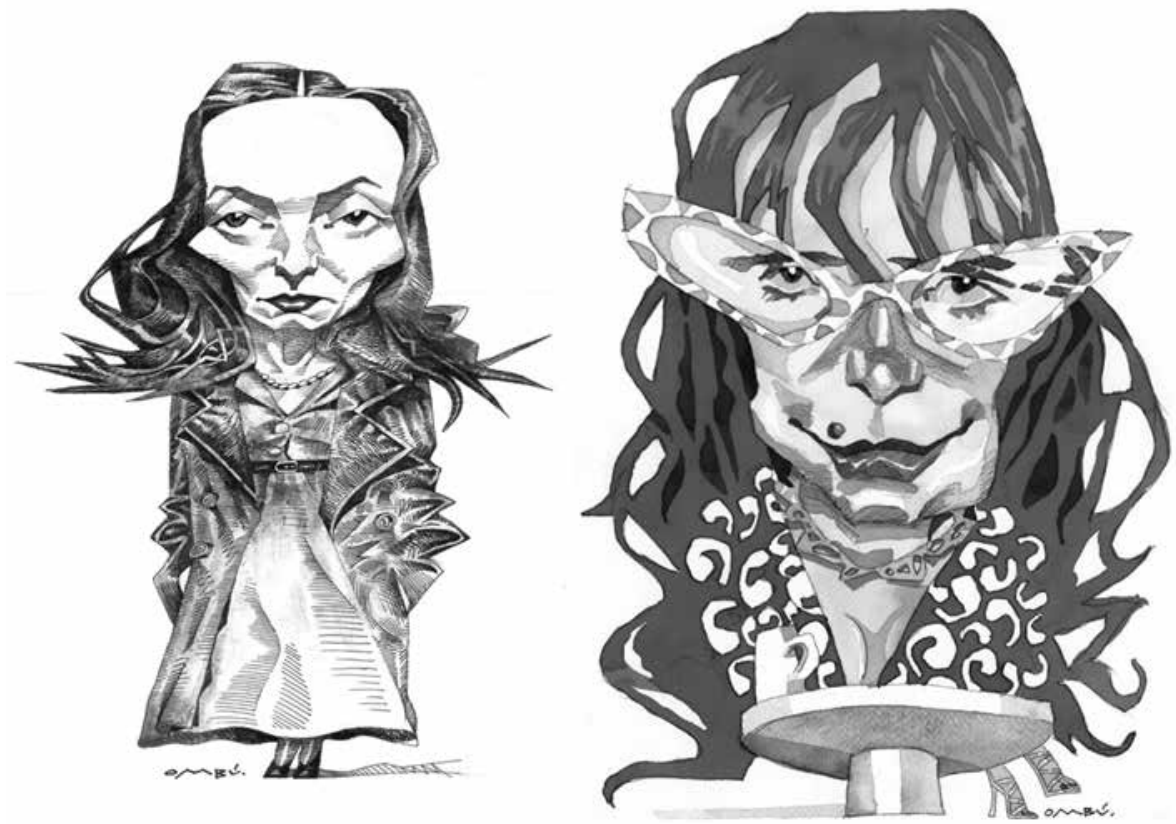

Idea Vilariño como Morticia en su andrógina gabardina existencialista. El dibujo reconoce su modelo en la fotografía tomada por Michel Sima en París, en 1954, que Idea impuso como su imagen oficial.

Marosa di Giorgio como la reina roja. Con el cabello en llamas y el título regio que tienen los personajes de su jardín, Reina Marosa reina en el café, desde una inconfundible y redonda mesa del Sorocabana, que fue a la vez su refugio y el escenario donde actuó su "personaje". Marosa fue nuestra primera dandy, y también, quizá, la última1.

Estas mitologías fueron creación propia de estas autoras en el sentido en que las pensó Pierre Michon en Cuerpos del rey y que estudió como Julio Premat en Héroes sin atributos ${ }^{2}$. El mito se inició para ambas en el acto demiúrgico de nombrarse. Idea recibió su nombre de un padre poeta y anarquista que eligió para sus cinco hijos nombres extraordinarios: Azul, Alma, Idea, Poema y Numen. Ella debió reconquistar el suyo, ya que en su infancia y primera juventud fue para todos Elena, su segundo nombre, una

\footnotetext{
1 El café como institución y como dispositivo para vivir una vida artística, tiene, también, una tradición de género. Delmira ya había dicho famosamente que le gustaría ir a París para poder sentarse en un café sin que toda la ciudad gritase escandalizada. Marosa que en el texto que dedicó a la Agustini recupera la anécdota, vivió toda su vida en los cafés, ámbito público que fue siempre la escena de los dandys en el Novecientos.

2 Michon, Pierre: Cuerpos del rey [2002], Barcelona, Anagrama, 2010. Premat, Julio: Héroes sin atributos: figuras de autor en la literatura argentina, Buenos Aires, Col. Tierra Firme, Fondo de Cultura Económica, 2009.
} 
concesión a la madre católica. "Idea" regresó con la edición de sus primeros poemas que firmó así, sin apellido. Marosa tuvo su nombre a partir del común María Rosa que figura en los documentos, y fabuló, reiteradamente, en sus libros, un origen: "Me parece que hoy, es el día de mi nacimiento. Papá y mamá dicen "Se llamará Marosa" escribe, por ejemplo, en La liebre de marzo (1981).

¿Por qué promover este encuentro, este diálogo imposible, entre dos planetas absolutos de nuestra poesía que, al parecer se ignoraron olímpicamente? ¿Por qué, si tampoco hubo un choque, una beligerancia, capaz de alentar la revisión? Mi interés nació al prestar atención a la insistencia con que se han leído sus obras desde la tradición de las poetas mujeres y los estudios de género, a pesar de la reticencia que ambas manifestaron respecto de estos abordajes y aun al feminismo. Mi propósito no es decidir desde la teoría, sino explorar el modo en que Idea y Marosa experimentaron la inscripción en esa tradición y atender las intervenciones y negociaciones que protagonizaron respecto a esa categoría. Pero también diré que lo intento porque el mito tiende a lo absoluto, y es un buen ejercicio historizarlo para corroer su blindaje y desplegar un sentido.

La convivencia en un campo intelectual acotado como el uruguayo dio oportunidad a que las órbitas divergentes de estas dos poetas/planetas se interceptasen esporádicamente. Elijo entre otros, un episodio que juzgo emblemático y, sin embargo, ha quedado enterrado y olvidado en páginas ya amarillentas de la prensa cultural, de donde lo exhumo.

El primer número del semanario Jaque salió el 18 de noviembre de 1983, en el contexto de la llamada apertura democrática y en un clima de efervescencia cívica. Para lucimiento de sus páginas culturales quiso estrenarse con dos escritores mayores que eran también un símbolo antidictatorial. Se eligió a Juan Carlos Onetti, representado por una colaboración inédita de las que, a partir del premio Cervantes, escribía para agencias desde España y que inició así la publicación de estas en Uruguay. Y se eligió también a Idea Vilariño que se negó a dar una entrevista, pero entregó tres poemas inéditos. Los editores dejaron constancia expresa de la fracasada entrevista y compensaron esa falta interrogando a dos poetas ("naturalmente" dos poetas mujeres) para que opinasen sobre su poesía de Idea sobre la generación del $45^{3}$. Una de las convocadas fue Marosa di Giorgio.

Leer hoy esas páginas produce una turbación retrospectiva. Toda la cobertura es paradigmática de lo que, con justeza, se llamó la "restauración" en el campo cultural, es decir, el intento por restablecer en todos ámbitos sociales -la universidad, los gremios, la prensa, los partidos políticos- el estado previo al golpe. El planteo periodístico en relación con la literatura era

\footnotetext{
3 Lucy Garrido es quien escribe la presentación que acompaña los poemas inéditos, "Desde el incómodo borde del abismo", Jaque No 1, 18.XI.1983, p. 3. Los tres poemas publicados no llevan título. El más largo, fechado en 1979, va a formar parte de su Poesía completa, despojado de su primera estrofa, y con el título de "Y seguirá sin mí", p. 117, el tercero, de solo cuatro versos, va a integrar No, con el número 14, en la Poesía completa, con pocas variaciones en la separación de los versos.
} 
otra forma de negar el tiempo transcurrido. Recurro otra vez al archivo de prensa, en este caso a la colección de Marcha en los años previos al golpe, para ilustrar mejor estas bienintencionadas y equívocas operaciones. En los años setenta, la editorial ARCA, dirigida al igual que las páginas literarias de Marcha por Ángel Rama, publicitaba en ese semanario su colección de poesía con tres títulos consagratorios de poetas mujeres: Poesía 1941-1967 de Idea Vilariño (1970), Los papeles salvajes de Marosa di Giorgio (1971) y Oidor andante (1972) de Ida Vitale. En un aviso se los proponía como "acontecimientos" en la trayectoria de cada poeta, por ser la primera reunión ampliada de la obra en el caso de las dos primeras y, en el de Ida, porque volvía a publicar después de un silencio de una década. En idéntico formato, los volúmenes solo se diferenciaban en sus colores. De algún modo esas publicaciones y la publicidad que merecieron eran síntoma de una cierta paridad en el reconocimiento y legitimación de esas tres grandes voces. No digo que las ediciones o el aviso prueben una convivencia idílica -nunca la factura de un canon lo es- en esas mismas fechas y en esas mismas páginas, es posible leer la división de aguas que produjo la irrupción de la voz de Di Giorgio en la escena poética montevideana. La polémica era también, naturalmente, un tácito homenaje a esa voz nueva y extraña 4 .

En las páginas de Jaque, diez años después, el lugar que se da a Idea y a Marosa es asimétrico y marca un retroceso respecto de la escena registrada en Marcha. Una década de censura y de aislamiento en dictadura puede explicar la involución. Jaque inaugura en el año de su publicación, un tiempo esperanzado capaz de soñar un país en el que ningún escritor volviese a estar proscripto, pero a la vez comete un crimen impremeditado. He revisado el archivo de Marosa que guarda su hermana Nidia y contiene abundantes recortes de prensa; comprensiblemente, no guardó entre estos el primer número de Jaque en el que la interrogaron acerca de la poesía de Vilariño. Debió ser un trago duro que, como se verá más adelante, ella resolvió al responder 5 . Más allá de la herida narcisista, el documento ilustra el daño que la dictadura produjo en su carrera literaria. Después de la edición consagratoria de Los papeles salvajes, pasaron siete años sin que Di Giorgio volviese a publicar6.

\footnotetext{
4 He referido la primera recepción crítica de la obra de Marosa di Giorgio en "Expiación y homenaje", Revista de la Biblioteca Nacional № 13, 2017, pp. 9-15. Una década antes, frente al desembarco de los Nocturnos y los Poemas de amor de Idea Vilariño hubo también una polémica. Ver Alicia Torres: "Emir Rodríguez Monegal artífice de la entrada de Idea Vilariño al canon literario nacional", Montevideo, Revista de la Biblioteca Nacional No 9, 2014, pp. 295-318.

5 La cuarta pregunta tiene una formulación cándida y alevosa: "¿Cree que se podría hablar de 'antes y después' de Idea Vilariño en la poesía uruguaya?". A lo que responde Marosa: "Este es un país con algunas figuras realmente importantes. Está Delmira. Y entre los que hicieron eclosión junto a Idea -para nombrar solo a un poeta mujer- hállase Amanda. Así que me parece más justo remitirme a lo del principio. No hacer comparaciones, contraposiciones. Tratar a cada artista como a alguien incomparable. Ya lo es cada ser humano, cuánto más un artista" (cit).

6 Ese hiato que va de 1972 a 1979 cuando publica Clavel y tenebrario (Arca), solo tuvo un alivio en la publicación en Venezuela de una plaquete mínima, ..., editada por quienes fueron los primeros en publicarla en la década del 50.
} 


\section{Deserciones en el gineceo}

Más allá de estas destrucciones por estancamiento, el formato de la propuesta periodística revela la ya mentada costumbre uruguaya de juzgar siempre la creación de una poeta mujer desde la categoría de género?.

Divergentes en tantas maneras, Marosa e Idea fueron reticentes a identificarse como mujeres escritoras y sostuvieron una relación compleja, mayormente hostil, con el feminismo. La última respuesta de Marosa di Giorgio al citado cuestionario, por ejemplo, cuestiona sutilmente el modelo de la estirpe femenina. La pregunta no era sutil: "¿Cree que se podría hablar de "un antes y un después" de Idea Vilariño en la poesía uruguaya?". A lo que responde con discreta contundencia:

Este es un país con algunas figuras realmente importantes. Está Delmira. Y entre los que hicieron eclosión junto a Idea -para nombrar solo a una poeta mujer- hállase Amanda. Así que me parece más justo remitirme a lo del principio. No hacer comparaciones, contraposiciones. Tratar a cada artista como a alguien incomparable. Ya lo es cada ser humano, cuánto más un artista.

Reparo en ese "para nombrar solo a una poeta mujer" que desliza discretamente Di Giorgio. Interrogada en otra ocasión respecto de la literatura femenina, Marosa será radical: "el arte es lo que es. No puede tener progreso ni sexo"8.

Una actitud similar tuvo Idea Vilariño. En el prólogo a su Antología poética de mujeres hispanoamericanas que hizo por encargo hacia el final de su vida, expresa sus salvedades de manera parecida a la de Marosa:

Una antología de la poesía escrita por mujeres, en español, en Latinoamérica, y limitada por decisión del editor, a un período [...] acota bastante la elección, deja mucho afuera, no solo lo escrito por hombres, sino también lo escrito en otras lenguas -el portugués, el francés, las lenguas indígenas ${ }^{9}$.

Al igual que Marosa, Idea señala la ausencia de "lo escrito por hombres" y consigna otras variables de exclusión. Aun así, en ese mismo prólogo,

\footnotetext{
7 Lucy Garrido que tuvo a cargo aquellas páginas, es profesora de Literatura y una destacada feminista que adelantó la agenda de reivindicaciones en un país que, después de haber sido una pionero a principios de siglo en legislar el divorcio y otros beneficios para las mujeres bajo el batllismo, estaba en los ochenta a la zaga en todos estos temas.

8 Delgado Aparaín, Mario (entrevista): No develarás el misterio, Buenos Aires, Cuenco de Plata.

9 En el espacio entre corchetes decía Idea: "que con algunas salvedades equivale aproximadamente al que en nuestro país se abre con la "generación del novecientos" y se cierra con la "del cuarenta y cinco"'", lo que induce a pensar que la antóloga se manejó con la cronología de su generación, aunque incluye muchas poetas menores. Antología poética de mujeres hispanoamericanas fue un proyecto realizado para la editorial Banda Oriental y se publicó en Montevideo, en 2001.
} 
denuncia a las antologías de poesía latinoamericana "hechas casi siempre por hombres, que ignoraron olímpicamente la escritura femenina" (7).

Hay otros documentos que exhiben la complejidad de sus actitudes. El archivo de otra escritora uruguaya, Clara Silva, poeta, narradora y ensayista, guarda una entrevista impresa (a ella) donde no falta la alusión al corpus de poesía femenina uruguaya. Silva menciona a diez poetas, pero no a Marosa. El recorte impreso está intervenido por Marosa que "protesta" el olvido ante su colega amiga10. Lo hace en buenos términos y prueba que fue entregado a Clara Silva por Marosa. No deja de ser conmovedor.

Existe cierta ambivalencia en estas dos poetas en su actitud frente a la tradición femenina en general y a la uruguaya en particular. Junto con las reiteradas protestas, reticencias o negaciones, hubo también una labor que cada una, a su tiempo, hizo respecto de esa tradición. Marosa escribió varias siluetas de escritoras uruguayas, que se recuperaron póstumamente en Otras vidas (2018) ${ }^{11}$, breve miscelánea de lo que Marosa esribió de otros escritores, donde lo relevante es el trabajo del corpus femenino asimilable en muchos sentidos a la antología de poetas hispanoamericanas ya citada que realizó Vilariño.

Esos trabajos, surgidos por iniciativa de otros, dejaron la huella -débil- de un reconocimiento mutuo: entre las once autoras uruguayas que incluye Idea en su antología, está Marosa y entre las breves siluetas que escribió Marosa, está Idea, pero tampoco es mucho. Idea no dejó juicio en sus antologadas y Marosa cumplió formal y escuetamente con los nombres que le eran menos afines, entre otros, el de Idea.

Ambas sin embargo fueron sensibles al canon de pertenencia por el que operaron mediante la incorporación de nombres y estuvieron asimismo atentas en la elección de sus precursoras. Sus coincidencias y diferencias en el cruce de esos dos planos establece un juego y libra una contienda que diseña y dirime sus poéticas.

En el canon femenino uruguayo Delmira Agustini ha impuesto la unanimidad. También Ida Vitale y Amanda Berenguer escribieron sobre su obra y le profesaron un razonado fervor, la citada Clara Silva fue su mejor biógrafa, pero para Idea y para Marosa, la admiración transcurre en el orden de la intimidad. Hay una entrada en el Diario de juventud donde Idea -tiene entonces veintitrés años- confiesa la emoción que sintió cuando tuvo entre sus manos los cuadernos de Delmira y lamenta no haber podido estar a solas con ellos. Su deseo equipara la poesía a la pasión y eso explica el anhelo de correspondencia y exclusividad.

10 Marosa señala una primera declaración de Clara donde reconoce referencias a su mundo y escribe: "Aquí estoy", luego hace una marca sobre la relación de poetas mencionadas y escribe "pero, acá, no ¿̇por qué? Y se despide y firma: "Disculpa, Cariños, Marosa". Colección Clara Silva, Carpeta I, Impresos. Archivo Literario, Biblioteca Nacional de Uruguay.

11 Marosa di Giorgio: Otras vidas, edición de Nidia di Giorgio, prólogo de Eduardo Espina, Buenos Aires, Adriana Hidalgo, 2018. 
Marosa dedicó dos textos a Agustini, algo excepcional en su magra producción crítica. El más extenso concluye que Delmira "no podría casarse sino con ella misma". La fórmula es la misma que, en Los papeles salvajes, da la voz narradora para explicar por qué no puede casarse como las otras mujeres: "¿no ven mi vestido blanco, mi diadema de desposada sin novio, sin marido? Como si estuviera casada conmigo misma" (301).

Idea sostuvo por Agustini un interés constante que plasmó en varios artículos, en fichas de diccionarios, en los cursos que dio en la Universidad, y sobre la que proyectó hacerse cargo de una edición crítica para la colección Archives, que no llegó a concretar ${ }^{12}$. En 1986, al cumplirse el centenario de la muerte de Agustini, publicó "Una amorosa" donde ya el título condensa y confiesa una afinidad y el reconocimiento de su obra "como una poesía del cuerpo, pero del cuerpo como campo agónico de lo erótico". Ambas encontraron en Delmira un modelo, un "sensitivo espejo"13 que resultó dar reflejos opuestos.

Otro es el caso respecto de Juana de Ibarbourou, otra poeta icónica del Uruguay. Al final de su vida, Idea admite a Juana en su antología, pero en su juventud de crítica militante, compartió el gesto parricida de su generación, especialmente encarnizada con los poetas del 20. En 1951 dedica una dura su reseña a "Perdida", en Número, revista donde ejerció la hegemonía de la crítica de poesía14. Marosa, en cambio, escribe sobre Juana desde una emocionada intimidad: "Vi solo una vez a Juana de Ibarbourou [...] Yo tenía un vestido blanco, de vidrio. Y ella iba de negro con perla". La imagen elige la metáfora del espejo y preanuncia alguna de las lecturas fermentales que se han hecho sobre esta filiación. Leer a Marosa como un reflejo en negativo de Juana. Reconocer la identidad del paisaje, los motivos, la infancia, la sensualidad, pero invertidos. Ariel Schettini ha ensayado esa interpretación que escucha el eco y el contragolpe con que Los papeles salvajes replican a la Raíz salvaje de Ibarbourou y ve a Marosa como su heredera y, a la vez, su detractora ${ }^{15}$. Sin embargo, su admiración por Juana era más acotada que la que profesó a Delmira. Hay una primera versión de ese breve texto apologético, donde Marosa al hacer el balance de la producción de Ibarbourou, concluye "Deja algunos poemas (¿una docena?) trémulos, valiosos. Y la leyenda. No se necesita más", que luego, sin desdecirse, va a corregir por "deja una docena de poemas trémulos... en medio de una obra amplia y delicadísima..."16.

\footnotetext{
12 Los textos de Idea sobre Agustini acaban de ser publicados en De la poesía y los poetas, Montevideo, Clásicos uruguayos, 2018, recopilación y prólogo de Ana Inés Larre Borges, pp. 135-154.

13 Tomo en préstamo la cita que sirve de titulo al artículo de Carina Blixen "Delmira Agustini: el sensitivo espejo", en Idea, Revista de la Biblioteca Nacional, No 9, Montevideo, 2014, pp.

14 Recopilado en De la poesía y los poetas, cit. p. 179.

15 Es parte del razonamiento de Ariel Schettini: "Ya en la idea de la "raíz" salvaje estaba el nacimiento, en los "papeles", su disolución". En "Marosa di Giorgio, la aprendiz de bruja", Revista de la Biblioteca Nacional No 13, Montevideo, 2017, pp. 182-189.

16 En correspondencia con Jorge Arbeleche que fue quien le pidió el texto para incluirlo en una edición de Poesía de Ibarbourou editada por el Estado en 2000 (Archivo Literario Biblioteca Nacional; Colección Marosa di Giorgio, Carpeta: Varios).
} 
Podría postularse que Marosa tuvo frente a Idea una actitud similar a la que esta tuvo para con Juana. En modalidad más tácita frente a los modos más combativos y más intelectuales de Vilariño, es posible reconocer un patrón que se reitera y que sostiene la tradición de una lírica femenina. Entre las fricciones y las facciones, las reivindicaciones y las afinidades que acompañan todo ejercicio poético, ambas estuvieron atentas a la especificidad de una tradición femenina. Actuaron con libertad y negociaron su ambivalencia, sosteniendo sus principios, exponiendo sus salvedades y, al mismo tiempo que jugaron según las reglas de su tiempo, contribuyeron a cambiarlas.

\section{Señas de identidad}

Aunque Marosa e Idea se mantuvieron refractarias al feminismo y ajenas a sus teorizaciones en arte y literatura, su poesía (la de ambas) está atravesada por la idea, casi obsesión, de una identidad en crisis. Es posible verlas como involuntarias precursoras que alertaran desde el centro de su obra sobre un problema que ha estado en la agenda del feminismo desde las teorizaciones de Simone de Beuvoir en El segundo sexo y se ha hecho compleja y desarrollado desde entonces. En Trouble gender (El género en disputa 1990), Judith Butler observó que la reconceptualización de la identidad como una construcción histórica y personal abrió posibilidades de autonomía para el sujeto, antes clausuradas por la teoría esencialista de las identidades como algo dado y fijo ${ }^{17}$. El tema de la identidad, su cuestionamiento, tiene en la poesía de Idea y de Marosa un lugar importante que es imposible relevar aquí, pero que está en el centro de sus poéticas. Vilariño -interrogada acerca de la frecuencia del tema en su poesía- afirmó que se trataba para ella de "un problema existencial, no un tópico literario" (Albistur 30).

"No sé quién soy/ mi nombre ya no me dice nada...Nada tiene que ver ya más con nada" dice en el poema 34 de No. La escisión del yo asedia obsesivamente su poesía nihilista, informa sus poemas, sus entrevistas, su Diario íntimo. Se busca el anclaje del yo en el cuerpo o se anhela ser nada, no ser, disolverse en la naturaleza, ser "una brisa suave/un pájaro liviano delirando en el aire / ser la noche". Pero al final acaba en negación: "Entonces no soy nadie" ("La metamorfosis" también de No).

Otro camino es la poesía. "Recuerdo que una noche en Cuba me puse a releer mis poemas para saber quién era"18. El gesto insomne de la mujer que lee sus poemas en medio de la noche para saber quién es, resulta una

\footnotetext{
17 "Paradoxically, the reconceptualization of identity as an effect, that is, as produced or generated, opens up possibilities of "agency" that are insidiously foreclosed by positions that take identity categories as foundational and fixed.[...] Construction is not opposed to agency; it is the necessary scene of agency, the very terms in which agency is articulated and becomes culturally intelligible. The critical task for feminism is not to establish a point of view outside of constructed identities; that conceit is the construction of an epistemological model that would disavow its own cultural location and, hence, promote itself as a global subject, a position that deploys precisely the imperialist strategies that feminism ought to criticize. The critical task is, rather, to locate strategies of subversive repetition" (Gender Trouble, 147) .

18 Entrevista de Mario Benedetti en Marcha, 1971, publicada en Idea La vida escrita, Cal y Canto - Academia Nacional de Letras, 2007, p. 63.
} 
imagen poderosa. La poeta se mira en su obra, como en un espejo, buscando reconocerse. Si el espejo es el lugar de Narciso, también es el lugar preciso donde yo es otro. Ya al final de su vida, Vilariño le dirá a Elena Poniatowska que la poesía fue lo único que no fue accidental en su vida, enumeró todo lo que hizo y pudo no hacer, traductora, profesora, estudiosa de ritmos, y solo puso aparte a la poesía. "Mi poesía soy yo" concluyó ${ }^{19}$.

"Yo soy los papeles salvajes" dijo Marosa di Giorgio también en una entrevista20. En su poesía la identidad en crisis afecta a todo el universo, un jardín original (natal y mítico) donde todo puede suceder y todo sucede. Un mundo en perpetua transformación donde no existen las fronteras entre lo fantástico y lo natural, lo soñado y lo vivido, entre los vivos y los muertos y donde se ha anulado toda jerarquía y abolido las categorías del orden natural de las cosas. Todo nace y muere y muta, todo retorna eternamente.

En su perpetuo devenir, la niña-mujer que cuenta el cuento, que recuerda, que inventa, tiene también una identidad voluble, y misteriosa. Puede decir "Soy siempre la misma niña a la sombra de los durazneros de mi padre" o, con igual certeza, "Soy la virgen. Me doy cuenta. [...] Quisiera ser una mujer en una de estas casas, ... pero, soy la Virgen". O puede preguntarse perpleja "¿Por qué soy una monje? [...] ¿Por qué no una mujer y sí un hada?" (Papeles salvajes 301).

En el jardín marosiano nadie puede estar seguro de quién es o por cuánto tiempo lo será. Por eso los nombres no están adheridos a la persona, ni a las cosas y las niñas les ponen apodos a las flores y a la virgen. Los nombres pueden ser transitorios: "En aquel tiempo, en los huertos, todas las mujeres se llamaban Estrella o Isabel" (250), o "Hay claveles en todas partes [...] fue tal su reyecía que a todas las niñas que nacieron se les adosó "Clavel": Ana Clavel, Iris Clavel, Josefa Clavel. Ese verano me nombraban "Rosa Clavel".

Esa arbitrariedad alcanza a la autora. En Los papeles salvajes, como señalamos al principio, se cuenta reiteradamente el nacimiento de Marosa.

El día de mi nacimiento [...] "toda la Creación estaba allí, esperando con ansiedad a aquel ser nuevo que venía. Y yo me despegué del vientre de mi madre y me erguí con el cabello rojo y mi extraña identidad" (300).

Esa extraña identidad, fue elegida, y sin ánimo de contrariar a su autora, está claro que se construyó a partir de la escritura.

Si en Idea Vilariño la crisis de identidad se presentaba como una pérdida y como un anhelo por recuperar la unidad perdida, en el universo de Di Giorgio la crisis se resuelve en una celebración de la diversidad y en una comunión panteísta que ha destronado a Dios y -como ocurre en Rosa mística-corona en su lugar a otra diosa que lleva su nombre y es la verdadera demiurga.

\footnotetext{
19 "La suplicante", entrevista de Elena Poniatowska, en La vida escrita, cit. p. 130

20 No develarás el misterio, Buenos Aires, Cuenco de plata, 2010.
} 
Si las diferencias entre las dos poetas son evidentes, las reúne el hecho de que sus respuestas a la crisis del sujeto que dieron desde la poesía con intensidad y audacia, inspiraron lecturas liberadoras y fervores de emancipación femenina y de resistencia a otros abusos y sometimientos. Y, aunque sería tal vez temerario afirmar que Idea o Marosa hubiesen estado de acuerdo con esas interpretaciones, es lo que ha sucedido. 